\title{
On the Determination of Radioactive Hydrogen
}

\author{
LARS MELANDER
}

Nobel Institute for Physics, Stockholm, Sweden

\begin{abstract}
Several more or less complete descriptions of methods for the quantitative Ddetermination of radioactive hydrogen (tritium) have already been published ${ }^{c f .1-8}$. The apparatus described below involves to a great extent the use of known facts. However, it may be of interest for chemists and biologists to learn how accurate tritium determinations may be made by rather simple means. In contradistinction to most methods previously described, neither the use of a high-vacuum pump, nor that of cooling agents such as liquid air, is needed in the present case.
\end{abstract}

\section{MAIN PRINCIPLES}

The tritium sample, which is assumed to be present as water, is reduced to hydrogen with magnesium turnings (as used by most other authors). A part of the active hydrogen gas is introduced together with methane into a GeigerMüller tube. Methane has been found to be a good quenching gas for use together with hydrogen in a counter tube connected with a Neher-Pickering quenching circuit. The pulses are registered by a scale of 64 and a mechanical recorder.

The remaining hydrogen may be diluted with inactive hydrogen, and a new measurement made after the first sample has been removed from the counter tube. In this way several activity values are obtained corresponding to decreasing concentrations of tritium, and the agreement between them may be checked in a simple graphical manner. (Figs. 5 and 6, see p. 445).

If the different parts of the apparatus are always flushed several times with pure gases before filling, it is quite satisfactory to use only a good rotary oil pump. All gas transfer within the apparatus takes place from higher to lower pressures and no pumping is necessary for this purpose. 


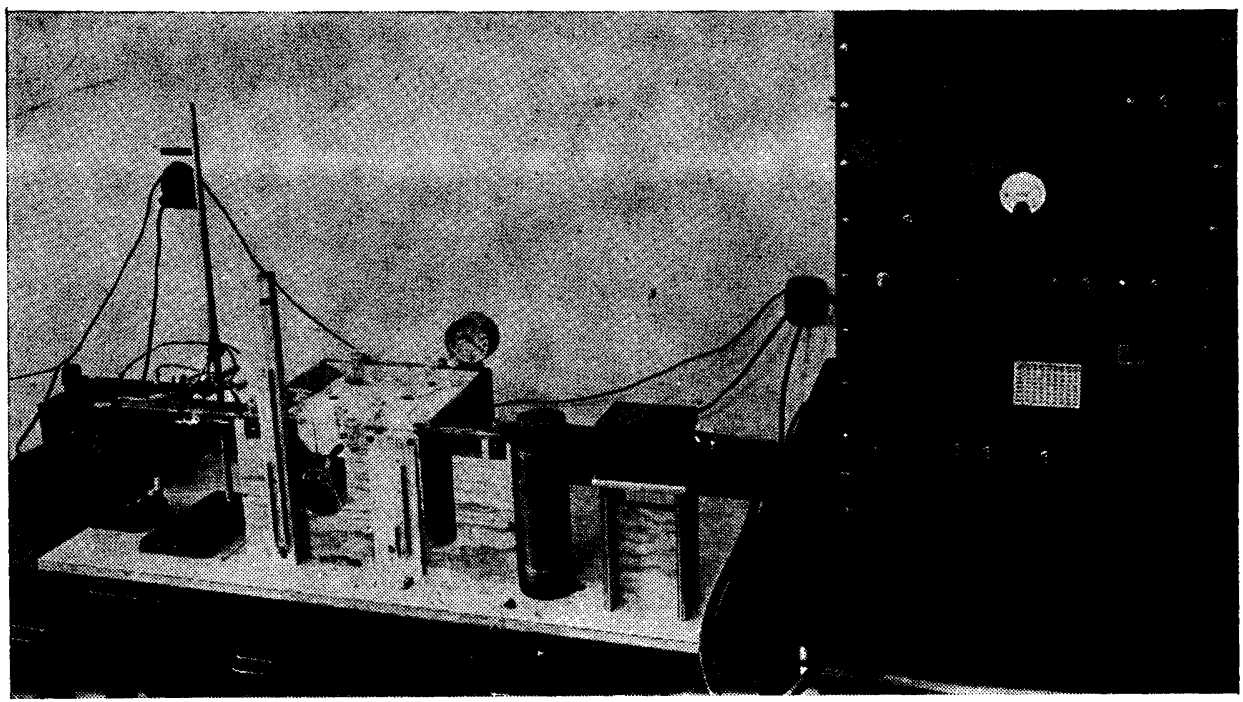

Fig. 1. Photograph of apparatus.

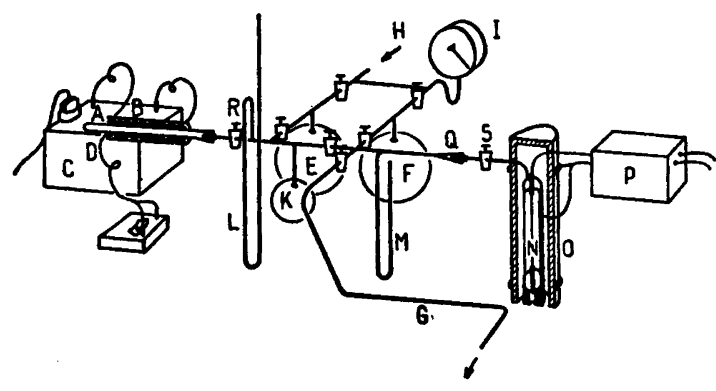

Fig. 2. Schematic drawing (partly in section) of the apparatus. A, furnace tube; $B$, heating coil; $C$, transformer; $D$, thermocouple; $E, F$, storage bulbs for inactive hydrogen and methane resp.; $G$, to rotary oil vacuum pump; $H$, gas inlet; $I$, metal vacuum gauge; $K$, bulb for active hydrogen; $L, M$, mercury manometers; $N$, Geiger-Müller tube; $O$, lead shielding; $P$, pre-amplifier; $Q$, ground joint; $R, S$, stopcocks.

\section{APPARATUS}

The apparatus is illustrated in Fig. 1, and in Fig. 2 a corresponding schematic drawing (partly in section) is given.

$A$ is a Jena Geräte tube (of about $1 \mathrm{~cm}$ diameter and $21 \mathrm{~cm}$ length), connected to the apparatus by a ground joint, and closed in the other end. It is heated by means of a Kanthal wire coil, mounted on a Supremax glass tube and protected by a Jena Geräte tube B. In this furnace the reduction is carried out. The transformer $\mathrm{C}$ gives the heating current, and the temperature is measured by means of a thermocouple $\mathrm{D}$.

The bulbs $\mathrm{E}$ and $\mathrm{F}$ are containers (1 litre) for hydrogen and methane respectively. They are evacuated through $\mathrm{G}$, which is connected to a rotary oil pump. The gases are introduced through $\mathrm{H}$ and the filling pressure measured by the metal vacuum gauge $\mathrm{I}$. The gases used are ordinary hydrogen from Nordiska Syrgasverken and methane, c. p., 
from the Matheson Co. In the bulb $\mathrm{K}(250 \mathrm{ml})$ the active hydrogen is collected and mixed with inactive hydrogen from $E$. The pressure in $K$ is measured by the mercury manometer $L$. $M$ is another mercury manometer which serves to measure the filling pressures of the Geiger-Müller tube N.

The Geiger-Müller tube $\mathrm{N}$ consists of a copper tube of about $3 \mathrm{~cm}$ diameter and $11.5 \mathrm{~cm}$ length, ending in two rings of kovar alloy, to which Schönander kovar glass is sealed. The anode is a $0.20 \mathrm{~mm}$ tungsten wire. This counter tube is shielded by a lead cylinder $O$ of $1 \mathrm{~cm}$ thickness. $P$ is a pre-amplifier, which is connected to a scale and high-voltage supply. $\mathbf{Q}$ is a ground joint connecting parts made of different kinds of glass.

\section{EXPERIMENTAL PROCEDURE}

About $40 \mathrm{mg}$ of the active water is introduced into a small weighed glass ampoule, the tip of which should be very thin. The ampoule is sealed off and weighed again. (The weight of the water serves as a check on the amount of hydrogen obtained in the reduction.)

The ampoule is introduced into the furnace tube with its tip against the closed end of the latter. A piece of iron and finally a layer of about $12 \mathrm{~cm}$ length of magnesium turnings (as used for Grignard reactions) are introduced. The bulbs $E$ and $F$ have previously been filled with hydrogen and methane to almost atmospheric pressure, and now the bulb $\mathrm{K}$ and the furnace are evacuated through $\mathrm{G}$. The furnace is heated, and when $575^{\circ} \mathrm{C}$ is reached, the ampoule is forced against the glass wall at the end of the tube and the tip broken by means of the iron piece, which is operated from the outside with a magnet. The heating coil is slowly moved towards the ampoule and the water slowly evaporated and forced through the magnesium layer. Some air is always present in the ampoule, but it will be taken up by the magnesium. The hydrogen formed is collected in the bulb $\mathbf{K}$, and the course of the reaction is followed on the manometer $\mathbf{L}$. About 15 minutes is sufficient time for the reduction. When the pressure in $\mathrm{K}$ rises no further and agrees with that calculated from the weight of the sample and the volumes and temperatures of $K$ and $A$, the stopcock $R$ is closed. Since the specific activity is to be determined it is of no consequence that some active hydrogen is left in the furnace.

The counter tube, which should have been flushed with methane and evacuated several times, is filled with $10 \mathrm{~mm}$ mercury pressure of methane and about $90 \mathrm{~mm}$ of the active hydrogen. Finally, the stopcock $S$ is closed. It is advantageous to record the complete characteristic curve and take the activity from the flattest part of the plateau.

After the activity measurement the counter tube is evacuated and flushed with methane. The remaining active hydrogen in $\mathrm{K}$ is diluted with inactive hydrogen from $\mathrm{E}$, and a part of the diluted activity is introduced into the counter tube and measured, etc. In this manner several activity values corresponding to different concentrations are obtained in a decreasing series.

The background should be determined with inactive hydrogen before and after the determination of the series of active samples.

\section{PREPARATION OF TRITIUM}

As described in several papers, the tritium is easily obtained from beryllium targets used for neutron production in the cyclotron. In the present case some milligrams of 


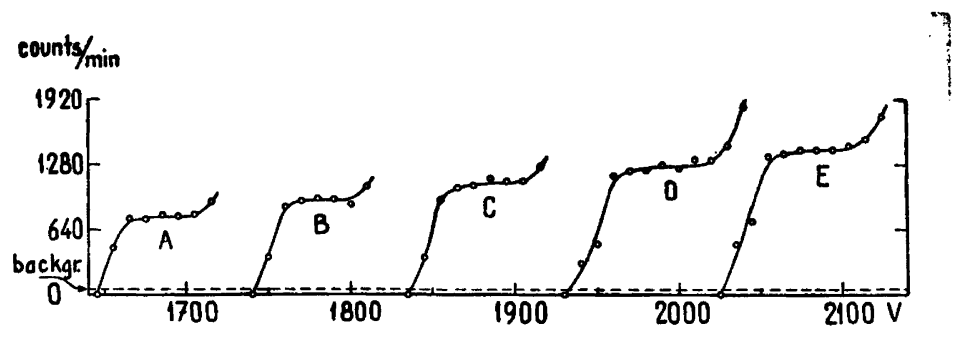

Fig. 3. Characteristic curves of the Geiger-Müller tube corresponding to different hydrogen filling pressures, $A, 60.0 ; B, 73.6 ; C, 89.0 ; D, 105.0 ; \mathrm{E}, 119.0 \mathrm{~mm}\left(\mathrm{HT}+\mathrm{H}_{2}\right)$ with constant specific activity; always $10 \mathrm{~mm} \mathrm{CH}_{4}$.

beryllium filings from an old target, bombarded with 6.5 Mev deuterons, were heated to bright red heat in a current of oxygen in a quartz tube for 1 hour ${ }^{9}$. As it was unnecessary to have an exceptionally high specific activity, the oxygen was moistened in order to provide a carrier for the active water, which was collected in a liquid air trap. Later the water was distilled under reduced pressure into a small storage bottle and some wash water added. The result was about $0.3 \mathrm{~g}$ water with a total activity of about 1.7 . $10^{7}$ disintegrations per minute or a specific activity of $10^{6}$ disintegrations per millimole per minute. If desired, a higher specific activity might have been obtained by the use of less carrier water.

\section{RESULTS}

Background. The background has been found to be 53 counts per minute when the hydrogen pressure is $90 \mathrm{~mm}$. Since the effective zone of the counter tube contains about $0.25 \mathrm{mmol}$ hydrogen at $90 \mathrm{~mm}$ pressure, it is possible to determine specific activities of an order of magnitude as low as 100 disintegrations per millimole per minute.

Different filling pressures. In order to establish the influence of the filling pressure of hydrogen on the counting characteristic of the Geiger-Müller tube, $10 \mathrm{~mm}$ of methane was introduced, followed by an increasing amount of active hydrogen with constant specific activity. Fig. 3 shows the characteristic curves for different hydrogen pressures, and in Fig. 4 the different plateau positions are plotted against the hydrogen pressure. The points in the last plot are found to lie almost on a straight line cutting the activity axis at the background value, as required by the constant specific activity. Hence it is possible to use different hydrogen filling pressures and carry out the calculations on the assumption of proportionality between the measured activity and the true amount of tritium present. 


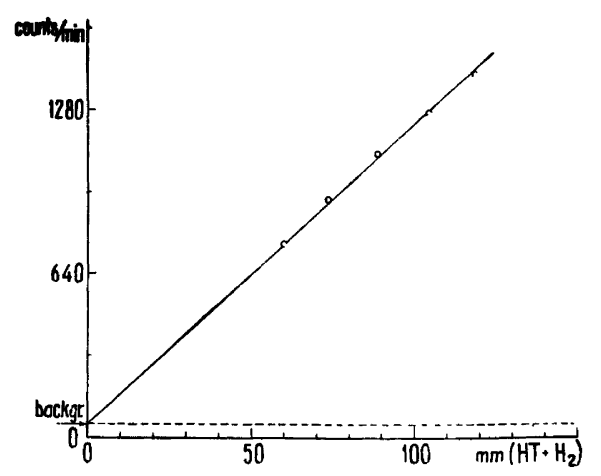

Fig. 4. Measured activity as a function of filling pressure of hydrogen (always $10 \mathrm{~mm}$ $\mathrm{CH}_{4}$, specific activity of hydrogen constant).

In these determinations the background was assumed to be the same for all fillings (that for $90 \mathrm{~mm} \mathrm{H}_{2}$ ), which is permissible since the background is entirely a wall effect.

Influence of specific activity of hydrogen. Fig. 5 shows the measured activity as a function of the specific activity. The filling pressures of hydrogen were $90 \mathrm{~mm}$. It is seen that the losses (due to the limited resolving power) become appreciable when the counting rate exceeds 6000 counts per minute. Below that counting rate the proportionality is good, as seen in Fig. 6, which is an enlargement of a part of Fig. 5. Simultaneously as the losses become appreciable (the three highest points in Fig. 5) the characteristic curves show a falling instead of rising tendency at high voltages, as pointed out by Kamen ?.

Pulse shape. The shape of the pulses was studied by means of a cathode ray oscillograph. With methane as quenching gas they showed a good aperiodic course. In another counter tube used before that described above, the shape was the same with methane, but with $10 \mathrm{~mm}$ alcohol a periodic course was obtained and correspondingly the number of counts registered was 2-3 times that obtained with methane.

Influence of reduction on isotopic ratio. In order to determine whether separation of hydrogen isotopes in the reduction will introduce considerable errors, two water samples of quite different specific activity were reduced and the activities compared (these two measurements were carried out with the old Geiger-Müller tube mentioned in the previous paragraph). For the second experiment a part of the water used in the first one was diluted.51.9 times. The specific activity ratio found was 50.0. (Weighing errors from the dilution have to be taken into account in the comparison of these figures.) Thus it is evident that almost no, if any, error is introduced in these (relative) measurements by isotopic separation. 


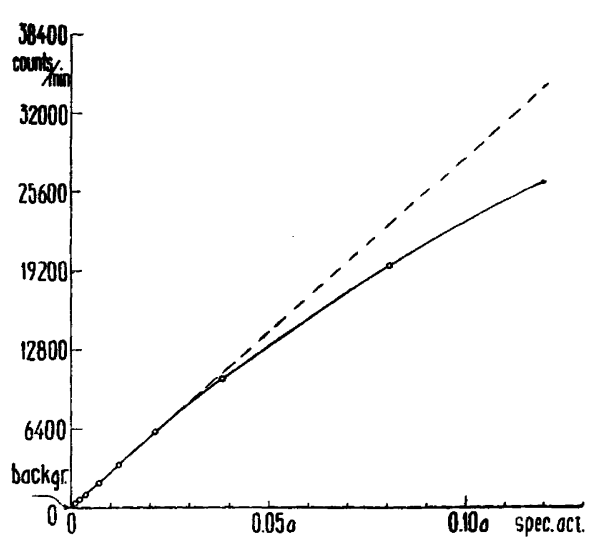

Fig. 5. Measured activity as a function of the specific activity of hydrogen $\left(10 \mathrm{~mm} \mathrm{CH}_{4}\right.$, $90 \mathrm{~mm}\left(\mathrm{H}_{2}+\mathrm{HT}\right), a=$ spec. act. of original tritium preparation).

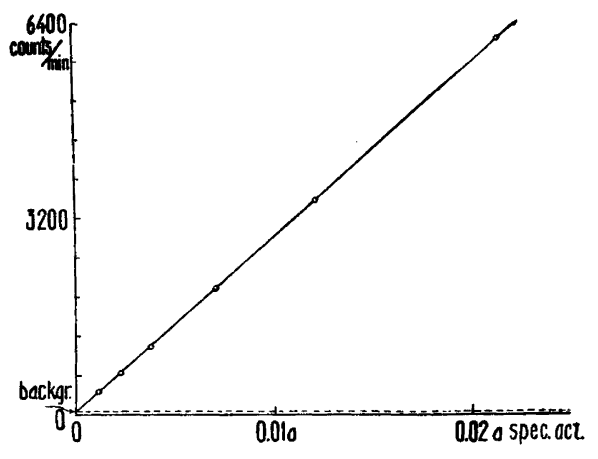

Fig. 6. Measured activity as a function of the specific activity of hydrogen (enlargement of a part of Fig. 5 ).

From the above results the accuracy in the determination of the specific activity of hydrogen in water is estimated at about $\pm 2 \%$.

\section{SUMMARY}

A simple apparatus for the determination of radioactive hydrogen in water is described. The water is reduced by means of magnesium, and the hydrogen introduced into a Geiger-Müller tube (the same method in principle as used by other authors). Methane has been found to be a good quenching gas for use together with hydrogen.

By means of control experiments it has been shown that the measured activity is proportional to the amount of tritium present in the counter tube. This holds independently of the total hydrogen pressure and the absolute amount of tritium over large intervals. It has also been shown that probable separation of isotopes in the reduction introduces no appreciable error.

The accuracy in the determination of tritium in water is estimated at $\pm 2 \%$.

In conclusion I wish to thank the Head of the Institute, Professor Manne Siegbahn, for his kind interest in this work. Mr. Björn Åström, Civ.ing., has constructed the electric equipment, and I also wish to thank him as well as Prof. H. Slätis for valuable discussions. 


\section{REFERENCES}

1. Allen, M. B., and Ruben, S. J. Am. Chem. Soc. 64 (1942) 948.

2. Harman, D., Stewart, T. D., and Ruben, S. J. Am. Chem. Soc. 64 (1942) 2294.

3. Norris, T. H., Ruben, S., and Allen, M. B. J. Am. Chem. Soc. 64 (1942) 3037.

4. Henriques, F. C. Jr., and Margnetti, C. Ind. Eng. Chem. An. Ed. 18 (1946) 420.

5. Eidinoff, M. L. J. Am. Chem. Soc. 69 (1947) 2504, 2507.

6. Joris, G. G., and Taylor, H. S. J. Chem. Phys. 16 (1948) 45.

7. Kamen, M. D. Radioactive tracers in biology New York (1948) Fig. 18.

8. Reid A.F. In the symposium: Preparation and measurement of isotopic tracers Michigan (1946).

9. Kamen, M. D. In the same symposium as ref. 8 . 